\title{
HOLISTIC TRAINING FOR TEACHERS OF HIGHER EDUCATION
}

\author{
Vijayalakshmi Ramamohan ${ }^{1}$, K J Sarma ${ }^{2}$ \\ ${ }^{1}$ SMIEEE Institute for Human Empowerment Studies, HYDERABAD- 500036. \\ ${ }^{2}$ Malla Reddy Engineering College(A), Dhulpally, Secunderabad-500 100 \\ ${ }^{1}$ Vlr.sarma@gmail.com, ${ }^{2}$ jskalavendi@gmail.com
}

\begin{abstract}
We are all concerned with the continuing inflation in India, since the time of independence. Obviously the economy depended on the production of goods (industrial, agricultural etc.) and the positive productive services. These in turn depend and are responsible for the clean produce and clean services for development. Generally human beings of working age group is responsible for the improving the production and GDP. Also in order to serve the society the vision must be "To better serve humanity, engineers must at least attempt to understand the human condition in all its complexity." A holistic approach to leaning and teacher interaction - would be more helpful. We need to circumvent the existing knowledge, investigate and integrate the factors for the development of critical learning. The competence of holistic teaching is the ability of the teachers as a whole and balanced encompasses the aspects of teaching knowledge, teaching skills, the emotional, and spiritual of the teacher, so that the character and values can be obtained by students through the process of teaching and learning.
\end{abstract}

\footnotetext{
Vijayalakshmi Ramamohan ${ }^{1}$

${ }^{1}$ SMIEEE Institute for Human Empowerment Studies, HYDERABAD- 500036.

${ }^{1}$ Vlr.sarma@gmail.com
}

\section{INTRODUCTION:}

\author{
We Can Not Always Build The Future For Our Youth, \\ But We Can Build The Youth For Our Future. - \\ Franklin D. Roosevelt
}

By 2025, India will be amongst the youngest nations in the world. 2025 calls for a new vision and a new aspiration, and this is the genesis of the Higher Education in India. In 2025, we want to be pioneers of a higher education model that is not just the best in the world, but the best for the world in delivering social, economic and intellectual value par excellence. We can see that with an imaginative vision and committed leadership many positive developments are possible within a decade. In order to realize the goals in 2025, a transformative and innovative approach should be across all the levels of higher education: from curricula, best teaching and learning process to the use of technology to partnerships, governance sufficient finances. Making a rapid progress over the next decades would need committed and concerted efforts from all stakeholders involved like academia, industry, Community, and Government. Developing a vision for a distant future and working towards reaching there is a good way to keep on track.

Though higher education system has undergone many changes, the country has created additional capacity for a nearly 40 million students, but there is not much constructive quality produce. We need a deliberate strategy and an organized design of education system. We need a wide range of courses which improve common sense, knowledge in-general, integrated, analogous, constructive all-round thinking in the youngsters. In other words the education must aim at providing quality holistic education to India's masses, and play a major role in promoting quality, professionalism and innovation.

It has been envisaged that in the process of transforming the current system to a holistic state certain basic principles 
must be seriously considered in the curriculum development. The content must be structured so that the aspects related to 1. Holistic student development with respect to the needs of the country and the society, 2 . Responding to the community concern about young people, 3. Preparing the students for professional maturity with general education with lifelong benefits, 6. Uniqueness, Universal coverage, 6. Theory driven general education 7. Research driven general education.

A differentiated system be offered to students with a wide variety of unique and quality programs at both graduate and undergraduate levels of choices to students which effectively caters to a heterogeneous students with varying needs and demands.

In other words the graduate who has received high quality teaching is more likely to be adaptable, assured, innovative, entrepreneurial and employable in the broadest sense of the term. The graduate who has received a mediocre teaching has wasted a lot of their time and money and in a competitive job market is at a disadvantage. In many cases, stereotyped bookish teaching also directly discourages students from staying on in higher education, and contributes to the high dropout rates and lack of student success. It all depends on how we rear our children and offer positive multifaceted training programs to our youth during their true assimilation age group. The knowledge tools and knowledge-in-general is related to "howstuffworks". In turn training must prepare a whole man.

Teachers must understand that "We are all instructors to realize that the quality of the mental process, not the production of correct answers, is the measure of educative growth, something hardly less than a revolution in teaching would be worked." John Dewey, Democracy and Education (1916).

Gandhiji gave the concept of 3 r's and 3 HE's viz. Handpsychomotor domain/skills, Heart-spiritual domain/skills, Head-Cognitive domain/skills and 3r's: Read, write and arithmetic. Gandhiji emphasized certain ideals, practical work and the potentiality of students in education. It is education through which we can find out the potential of the students and teach them certain ideals which will help them to be a good citizen and through practical activities students will be in a position to think practically and they will be attentive and active, this will help them to mould their character.

"Education cannot be a business product or system. Education at the primary level has to be delivered in an integrated way by great teachers through good syllabus and promoting affinity between parents, students and teachers," Kalam said. Further he adds "It is not a great building or a great facility or great advertisements which gives quality, but lovable education and great teachers do."

Teachers must understand certain guiding principles like teaching and learning are fundamental core missions, active student - teacher involvement is essential in governance, curricular design, development and review, quality assurance and review procedures; preference of research over teaching in defining academic merit needs rebalancing; academic staff are employed not just to teach. To guide students with a high professional standard; the key responsibility of institutions is to ensure that their academic staff are well trained and qualified as professional teachers and not just qualified in a particular academic subject. This responsibility extends to ensuring new staff have a teaching qualification or equivalent and have access to credible teacher training courses in the early years of their career. This responsibility extends to providing opportunities for continuous professional career development as a professional teacher and not just as a subject/discipline specific. The key responsibility of academic staff is to ensure that they are qualified to teach and able to teach well; and this responsibility extends over their entire career from start to finish so that they remain up-to-date and proficient in the very best pedagogical practices that excellent teaching requires.

\section{HOLISTIC DEVELOPMENT:}

The all-round development is one aspect. Leadership development roles, professional development, cognitive development, sense of improving the GDP, sustained development, concern for greater perform-ability, working on global engineering challenges for the positive development etc.

As time is getting advanced into 21 st century, we would be required to investigate what are the main knowledge tools, how do we impart the tools in a more effective fashion, how do the trainers make good use in extending the same training to youngsters are the main issue in this paper.

Obviously the quality of learning experience is undoubtedly important and the current emphasis is on improving the quality of the teaching and learning situations is a positive development in higher education.

Descriptive findings showed that the four aspects of holistic competence is required in teaching namely aspects of teaching knowledge, teaching skills, emotional, and spiritual of teachers

A relatively limited attention has been paid to the role of higher education institutions on the initial education and 
training of adult educators-to-be; when compared to other fields of education.

Some of the approaches being

1. Reflective teaching practice - which is practical in UG, PG and doctoral programs.

2. Promotional intra-personal competencies, interpersonal relationships skills civic responsibilities and a sense of citizenship.

3. Concern for economic growth in India,

4. Positive attitude for the global development

5. Good Expression and communication skills.

Again as whole it is the university's role in nurturing the holistic development.

\section{ISSUES OF QUALITY TEACHING IN HIGHER EDUCATION:}

The main things are

1) In the first place the three questions we are concerned are viz a) "What is Quality Teaching and why is it important in higher education?" b) "How can teaching concretely be enhanced?" c) "How can one make sure Quality Teaching initiatives are effective?

2) Quality teaching has become an issue of importance in higher education and has been facing challenges due to increased international competition, increasing social and geographical diversity of the student body. But quality teaching lacks a clear definition, because quality can be regarded as an outcome or a property, or even a process. Also Quality teaching initiatives are very diverse both in nature and in function due to diversified as the goals and the scope. Quality Teaching requires that attention be given to the "Personal learning Environment" (Ellet, Loup, Culross, McMullen and Rugutt, 1997) of students.

3) quality of learning by improving the learning environment, Students have knowledge of the goals of the class, Students know what work must be done for the class Students perceive the teacher to be fair, the pace to be good• Students participate in-class $\bullet \quad$ Students relate to other students• Students can receive help from the teacher if needed.
According to Ex-Prime Minister of India Dr. Manmohan Singh "The time has come to create a second wave of institution building and of excellence in the fields of education, research and capability building". We need an educational system that is modern, liberal and can adapt to the changing needs of a changing society, a changing economy and a changing world. The thrust of public policy for higher education in India has to address these challenges. However, one university can't make much difference. If the government welcomes more such initiatives, the future will be ours. We will be able to match and compete with other countries and the dream to be the world's greatest economy won't be difficult to achieve.

We need to meet the changing needs of educators and the latest developments in education. It comprises of three components; two of which are delivered via e-learning. The components will help us gain the maximum benefit from the contact days, deepening our understanding of how enlightened learn and enabling us to plan, develop, deliver and evaluate training more effectively.

The training of trainers will be organized consist of intensive hands on training and the topics:

- $\quad$ qualifications framework and quality assurance;

- development of qualifications standards, including their learning outcomes and assessment criteria;

- development of occupational standards, curriculum development, teaching and learning strategies, innovative assessment methodologies, student-centered learning;

- validation of qualifications standards and occupational standards,

- $\quad$ use of qualifications standards and occupational standards for design of programmes,

- $\quad$ use of qualifications standards and occupational standards for validation of programmes,

- use of qualifications standards, occupational standards and study programmes for

other components of internal and external quality assurance system, principles of adult learning, and learning needs,

- $\quad$ building cross-sectoral competences of trainers.

It is more interesting to note the good qualities needed by a researcher in the dynamic parts of doing research. We can call these qualities as the good qualities on the process. They are as follows: Diligence and persistence, creativeness and innovativeness, objectiveness, open-mindedness, orderliness and cleanliness, cautious, accuracy and precision, 
quickness and responsiveness, Keenness, systematic and reasonableness, and cooperation and leadership.

Teachers will have to leverage their scholarly strengths to Foster multidisciplinary and multi-modal research, Inform public policy, Fuel economic development and the entrepreneurial spirit, Build energy capacity, Enlarge the food supply, Enhance national security, Strengthen the letters and the arts, Advance the professions, Innovate in technology, Generate advancements in health and the life sciences.

Patience, humility and flexibility are keys. Patience to understand that your research question can, and probably will change during the initial stages of your research. It is not written in stone (unless of course the research question has been set by your funding body) and the beauty of research is its ability to change things, including your very own research process.

\section{STRATEGIES:}

Teachers must explore multiple sources and ways for holistic purposes. Make up a strategy for holistic learning a frame work for change expanding engineering knowledge base. They must identify all the issues for holistic development and ways to promote holistic development. They should think of holistic social reality, tem-work and communication, engineering ethics and critical thinking, perceived obstacles of holistic engineering education,

Some other aspects are Engineering Research, Perspectives, Vision for Holistic Education For 2025,

Barriers To Quality Teaching And Learning like What Can Be Done About Them?, Institutional Leadership: TopDown And Bottom-Up, ( Six Sigama and Lean Six Sigma training, Skills 21st Century Teachers should Have, Promoting High Quality Learning?

Curriculum Design: Involving Students as Partners in Teaching and Learning, Multidisciplinarity For Better Outcomes, Internationalization, Globalization, and Mobility of Staff and Students.

Lerner Centered, Project Based Learning, \& Problem Based Learning, Intense Use Of Technology, Holistic Development, Holistic Support.

\section{CERTAIN KEY ACTIONS STEPS THOUGHT BY SOME STALWARTS:}

Other than the responsibilities of teachers the organizations also must have certain steps to be taken

A. Develop effective faculty-development programs in terms of content and structure
* Ensure fast and uninterrupted internet connectivity to deliver faculty training programs using virtual classrooms.

* Provide funding support to education institutions to enable them to organize activities such as summer workshops and exchange programs.

- Ensure active participation by best-in class faculty from top-tier institutions to be 'hubs' for training and development of junior and mid-level faculty members from other institutions.

B. Develop a structured and transparent framework to evaluate performance of faculty members

- Develop a transparent and effective performancebased remuneration system

- Implement a system of peer reviews and student feedback in all higher education institutions.

- Appoint independent committees in institutions to ensure accountability and transparency in implementation of these initiatives

C. Provide higher salaries and perquisites to attract high-quality research faculty

- Limit the teaching load of faculty members to enable them to focus on research.

- Upgrade research infrastructure to attract Indian research faculty working in world class foreign universities.

- Provide opportunities for consulting assignments and corresponding monetary benefits generated by these for faculty members.

- Sponsor faculty members participating in seminars and conferences across the world.

D. Create a governance structure with a professionally-run management that operates independent of the ownership of the higher education institution

- Devise a framework that clearly details roles and responsibilities of top management and faculty in institutional governance, as well as the roles of other stakeholders, including students, alumni, and employers, in ensuring effective governance.

- Create Boards of Management (BoMs) in every institution on similar lines as the Board of Directors of corporate organizations, consisting of a mix of elected and nominated representatives, with active participation/ representation of academia, alumni, and industry.

- The BoMs will be the apex governance body of institutions, and will further create appropriate committees with clearly defined responsibilities and accountability. 


\section{ASPIRATIONS FOR TEACHERS:}

We seek to make a significant contribution to the development of knowledge, to learning and teaching, to our students and to society. In accordance with this aspiration, we are committed to developing "globally focused graduates who are rigorous scholars, capable of leadership and professional practice in an international community" UNSW.

A good teaching and the imperative of research which critiques, refines, discards and advances human knowledge and understanding. Good teaching, in many subject areas, is only good to the extent that it is informed by the latest research. A good teacher, like a good graduate, is also an active learner, questioner and critical thinker. The good teacher aims to help the student be confident in handling the subject as it has developed so far, to be courageous in openness to new ideas, curious enough to seek new solutions and opportunities, and insightful enough to work well with others so that the flow of information and effort is maximized.

1. To keep track of challenges being come across the world: There have been some engineering challenges identified by the world engineering leaders of wisdom for the smooth flow of the economy and the life of people.

2. Technological Issues which help the economic growth and welfare of the country: More specifically India being a developing nation is also facing several social, economic, emotional and engineering challenges

3. Issues which are likely to broaden the thinking of the students: Improving the how and what of things and "howstuffworks", will improve the wisdom of the students, these must be shared without any bias. In thought process. There are of course other aspects related to behavioral.

4. Issues which help the understanding of professionalism and ethics: With advancement of the technology and haste of executing, without checking the optimal processes where ethics are violated, perhaps we need to trace the root cause.

5. Factors responsible for the technological convergence, institutional convergence and cultural convergence, where in teams will have to work towards common goals: As time is getting advanced the research is switching over from specialized knowledge to global knowledge. So it is expected that one must possess necessary fundamental knowledge tools of other branches. Also the common analogies.
6. Common sense issues related to technology: Teachers themselves are expected to have broadened thinking and the working of theory in practice.

7. Personal and professional growth of individuals.

8. Expressivity, connectivity where from guidance can be taken from peers: It is to promote freedom of expression and freedom of the press through sensitization and monitoring activities, as a central element in building strong democracies, contributing to good governance, promoting civic participation and the rule of law, and encouraging human development and security. In other words it is "Promoting the free flow of ideas by word and image".

9. An understanding of his egoism vs the egoism of partners: There must be a positive harmony of interests among free, rational humans, such that no moral agent can rationally coerce another person consistently with his own long-term self-interest.

10. Ability to ascertain the objectives, goals, strategies, general practices: i.e. Understand the nature of goals and objectives and why they are important. See how our thinking about goals and objectives has evolved. Know what characterizes good goals and objectives. Understand the roles of goals and objectives in employee performance reviews. Map out relationships among economic, social, and environmental goals and objectives. Set and manage your own goals and objectives.

11. Strategies for developing critical and computational Thinking: In order to ascertain the objective perception of the system.

12. Knowledge and expertise in using the cognitive skills for bridging the gap, between theory and practice: To resolve the longstanding tension between excellence and equity. Need for a Knowledge of the hemi-spheres of the brain.

13. Our attention to the major questions of society: Which value system should form the base of our society? What should the relationship between the individual and society look like? How are responsibilities divided among state, business and civil society?

14. The working of various technologies: Some fundamental aspects of the other fields like a computer science person must learn something related to electrical, electronics, mechanical, chemical and other engineering processes.

15. Concepts on which production of various goods are manufactured with help of modern information technology. 
16. Influencing the people by constructive means: A logical thinking without bias must remove the confusions.

17. How to become a thinker beyond times: The teachers be able to shape a vision of technology, education.

18. Managing yourself.

19. Foundations and relevance of Indian management thought and practice.

20. Concern, consistent aspiration and ability to trace the origin and development of ideas. If required.

21. World engineering challenges and concern like global warming, nitrogen cycle, depletion of resources, and benefits of certain engineering challenges: Knowledge of the engineering processes and the strategies for supplementing the people in crisis, as identified by National Academy of Engineers, USA.

22. Collaborative academic, social, emotional learning:

23. Concern to contributing to the positive development of the cause.

24. Bing engages in active learning.

25. Possible industry visits and rigorous manufacturing industrial experience for teachers: Every teacher must be having some experience of working in a manufacturing Industry and should be interested $\mathrm{t}$ exposed and renew thinking related to real life experiences.

26. Industrially experiences teachers will be an asset: The organizations must have teachers who are Having worked in Industry, and aware of with sound knowledge of manufacturing and industrial processes ( at both theory and practical levels ). An experience of introducing the subjects with the concept of " objective perception of reality "

27. Experiencing the nature.

28. Ability to create a threat by stories and resolving with solutions: The stories may related to real life experiences due to natural calamities and some may be relating to novels and dramas.

29. Sufficient wisdom: This will develop only when teachers develop openness to learn new things.

30. Working and sharing with blended teaching methodologies.

31. A friendly supportive and sportive outlook: This will be an asset which does not create tension in students will be responsible for expressing frankly. This may result in innovations.

32. Need to promote enthusiasm of social, emotional and academic learning.

33. Caring, Connected, Responsible, Contributing Problem Solver.
34. Standing erect in the instances of crisis: Students must be prepared for the unexpected crisis in life. This knowledge is related to enhancing endogenous parameters of skills.

\section{CONCLUSION:}

The best teaching and learning environments encourage students to develop confidence in their own creative abilities, strong community engagement and a sense of ethical responsibility allied to the humility that comes from understanding that learning is a lifelong phenomenon that demands a lifelong curiosity and commitment. The result of practicing the holistic approach has been sustained high levels of student attendance at lectures and seminars, improved progression, and appreciative and satisfied cohorts. The holistic approach has been developed over nine years of reflective teaching practice. Its aim is to develop critical learners who are confident and independent enough to act in real situations. The approach consists of five intertwined aspects of the teaching situation that reflects a rich social dynamics: knowledge, self, professional and personal development, discipline, and learning and teaching.

\section{REFERENCES:}

1. Holistic Learning in Engineering by Rama Bhat, 2007, National Conference on The spirit of Enquiry, Developing critical thinking, creativity and Community. McGraw Hill, 2007

2. Enhancing the engineering curriculum through holistic Engineering janelle macdougall, alan ham, and remon pop-iliev,

3. Helena Trbušić , Holistic education: the social reality of engineering, helena.trbusic@fsb.hr, Journal of Education Culture and Society No. 2_2013.

4. Challenges for Holistic Engineering Education Development in India, Zakir Husain, Deepak Kumar, International Journal of Evaluation and Research in Education (IJERE), Vol.3, No.1, March 2014, pp. 11 18.

5. A holistic view on the development of engineering students' flexible and creative problem solving.

J. Walther, Chantinee Boonchai, D. F. Radcliffe. www.sefi.be/wp-content/abstracts/1172.pdf

6. Domenico Grasso and Melody Brown Burkins; Beyond Technology: The Holistic Advantage, by, chapter 1; D. Grasso, M.B. Burkins (eds.), Holistic Engineering Education, 1, DOI 10.1007/978-1-4419-1393-7_1, C - Springer Science+Business Media, LLC 2010.

May 2006.

7. Fabrice Henard And Soleine Leprince-Ringuet, The Path To Quality Teaching In Higher Education; OECD, IMHE, 2008. 
8. Kathleen M. Quinlan, Developing the whole student, leading higher education initiatives that integrate mind and heart. Oxford Learning Institute, University of Oxford, 2011. 9. Systems Thinking, A Dissertation Presented to the Faculty of the Graduate School of Cornell University in Partial Fulfillment of the Requirements for the Degree of Doctor of Philosophy by Derek Anthony Cabrera, May 2006.

10. How should we measure higher education? A fundamental review of the Performance Indicators Part Two: The evidence report Emma Pollard, Matthew Williams, Joy Williams, Christine Bertram, and Jonathan Buzzeo, IES.

11. Educational Philosophy of Mahatma Gandhi with special reference to Basic education: An overview, by Srikanta Nandi, Tanmoy Pandit, Dr. Pankaj Kumar Paul; A PeerReviewed Bi-lingual International Journal of Humanities \& Social Science Volume-I, Issue-I, April 2015, Page No. 4652.

12.Sri Aurobindo, The Human Cycle The Ideal of Human Unity War and Self-Determination, Volume 25 The Complete Works Of Sri Aurobindo, SABDA Publications, Pondicherry. 1997. 